\title{
Finite Element Simulation of Forming Process for Automotive Components from Advanced High Strength Steel
}

\author{
Yachita Peraprutchaya ${ }^{1}$ and Surasak Suranantchai ${ }^{1}$ \\ ${ }^{1}$ King Mongkut's University of Technology Thonburi, Department of Tool and Materials Engineering, 126 Pracha Uthit Rd., Bang Mod, Thung \\ Kru, Bangkok 10140, Thailand
}

\begin{abstract}
Advance high strength (AHS) steel has been widely used in the automotive industry and order to reduce the weight of automotive components that effect to reduce fuel consumption, but vehicles maintain safety. However, forming process with AHS steel has many problems which the main defect was spring-back. Therefore, the usage of finite element (FE) method simulation with kinematic hardening materials model sustains and improve production processes. Yoshida-Uemori (Y-U) model is the one of kinematic hardening materials model that show the great capability for prediction of elastic recovery behavior. Consequencely, this work has been research on AHS steel as the NSC980D grade for automotive components in the drawing process and applied FE simulation with Y-U model to improve the production process. Moreover, NSC980D steel was inspected in tension-compression and tensile tests were proceeded. As a result, material parameters from testing simulate with designed die and improvement were shown. Finally, comparing FE simulation forming with experiment forming, showed FE simulation with Y-U model is suitable for prediction and process improvement.
\end{abstract}

\section{Introduction}

Nowadays, the trend of automotive industry has been developed automotive components in terms of quality, cost and delivery for increasing competitive of manufacturer and responding the demand of customers. The consumer demand focus on fuel economy. Consequently, manufacturers try to use AHS steel materials into production process for the intention of reducing weight but safety remaining [1].

However, forming process of AHS steel materials has more problems in strength of materials. The necessary defect in drawing process is spring-back effect especially in high strength materials. It was found that the materials with higher strength is more spring-back than lower strength materials [2]. The solution of improvement in production process is rather difficult by which waste of time and cost. Hence, it is necessary to use FE simulation to construct kinematic hardening materials model for analysis and improvement of die design process. It becomes necessary for producing process to reduce time and cost in trial out and error of die design process [3].

Recently, it has been studying and creating a variety of kinematic hardening materials model to describe plastic deformation behavior and forming prediction of materials. Each materials model is suitable for different application. Y-U model is the one of kinematic hardening materials model that shown the great capability for description about elastic recovery behavior and springback effect prediction. Some researches for NSC980D steel grade and Panel-RF FRT HRD vehicle component that was formed by drawing process. Moreover, FE simulation with Y-U model has been used for improving spring-back effect. Including, tensile testing and tensioncompression testing obtain materials parameters that required to simulation forming. For this research, the commercial program PAM-STAMP, based on FE, was applied to the die design. Finally, the result of FE forming simulation compare and analyze with experiment forming.

\section{Materials model}

This research concentrated to study on Y-U model with AHS steel NSC980D grade. Y-U model was constructed within two-surface plastic model of the Bauschinger effect, which is a kinematic hardening of yield surface and mixed isotropic-kinematic hardening of bounding surface. It has ability to describe the transient Bauchinger effect of high strength material deformation characterized by early re-yielding and smooth elastic-plastic transition with a change of work-hardening rate and the permanent softening characterized by stress offset in the region after the transient period, shown as Figure 1. And the workhardening stagnation appearing at the range of reverse deformation of high strength material behavior [4]. For applying this model, it is required many parameters from the mechanical properties testing of NSC980D, which was seven plasticity materials parameters $\left(Y, B, b, R_{s a t}, C\right.$, $k$, and $h)$ and three Young's modulus parameters $\left(E_{0}, E_{s a t}\right.$, 
and $\xi) . Y$ is the initial yield strength; $B$ is the initial size of bounding surface, $C$ is the material parameter for kinematic hardening rule of yield surface and its isotropic hardening component; $R_{\text {sat }}$ is the saturated value of the isotropic hardening stress at infinitely large; $k$ is a material parameter that control the rate of isotropic hardening; $b$ is kinematic/isotropic hardening of bounding surface parameter; $h$ is the materials parameter that controls the work-hardening stagnation; $E_{0}$ is the initial of Young's modulus; $E_{\text {sat }}$ is the saturation value of Young's modulus when the strain becomes infinite; and $\xi$ is the materials parameter that control the plastic-strain dependency of Young's modulus [5]. Those parameters of Y-U model can be obtained from the material testing data for AHS steel materials tests with tensioncompression testing. In addition, anisotropy parameters will be determined by some of conventional tests as uniaxial tensile test, etc. [6].

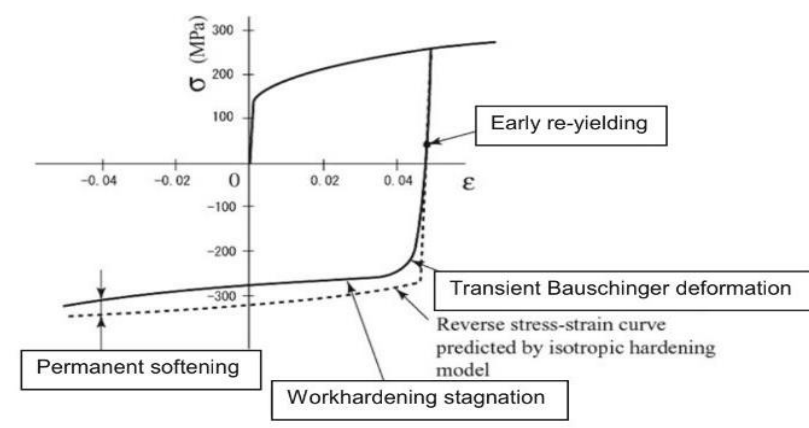

Figure 1. The illustration of two-surface plastic modeling [4]

\section{Materials testing and experiment}

In this research, the researchers tested on steel sheet grade NSC9890D, which is a dual phase steel, with 1.0 $\mathrm{mm}$ thickness. The mechanical properties of material were examined by tension-compression testing and uniaxial tensile testing for determine material parameters of Y-U model and some anisotropy parameters to apply with FE program.

\subsection{Tension-compression testing}

This testing was performed to total tension and compressive strain about 10 percent to obtain a saturated state of response to stress and strain. The tests describe Bauschinger effect during the reverse deformation, reyielding, transient Bauschinger deformation, workhardening stagnation and permanent softening behavior of AHS steel, that shown in Figure 1. The cyclic test has a spring fixture for prevent bending and has a digital image correlation (DIC) system for measuring the local displacement of specimen. From the cyclic test, the result is true stress - strain curve for determining of $\mathrm{Y}-\mathrm{U}$ parameters, as concluding with Table 1 . In addition, the material parameter that illustration the relationship of Young's modulus changing function and applied effective plastic strain, are given in Table 2.
Table 1. Material parameters of Y-U model for NSC980D steel testing from cyclic test

\begin{tabular}{|c|c|c|c|c|c|c|}
\hline $\begin{array}{c}\boldsymbol{Y} \\
{[\mathbf{M P a}]}\end{array}$ & $\begin{array}{c}\boldsymbol{B} \\
{[\mathbf{M P a}]}\end{array}$ & $\begin{array}{c}\boldsymbol{b} \\
{[\mathbf{M P a}]}\end{array}$ & $\begin{array}{c}\boldsymbol{R}_{\text {sat }} \\
{[\mathbf{M P a}]}\end{array}$ & $\mathbf{C}$ & $\mathbf{k}$ & $\mathbf{h}$ \\
\hline 739.36 & 918.94 & 24.55 & 290.24 & 200 & 16.09 & 0.5 \\
\hline
\end{tabular}

Table 2. The relationship between Young's modulus and plastic strain parameters [7]

\begin{tabular}{|c|c|c|}
\hline $\begin{array}{c}\boldsymbol{E}_{\boldsymbol{0}} \\
{[\mathbf{G P a}]}\end{array}$ & $\begin{array}{c}\boldsymbol{E}_{\text {sat }} \\
{[\mathbf{G P a}]}\end{array}$ & $\boldsymbol{\xi}$ \\
\hline 189.91 & 128.40 & 14.19 \\
\hline
\end{tabular}

\subsection{Uniaxial tensile testing}

Firstly, the uniaxial tensile testing was performed to determine the anisotropic plastic behaviors of steel examinations. The tensile testing was using hydraulic tensile test machine with constant crosshead speed of $0.05 \mathrm{~mm} / \mathrm{s}$ and record the image during the test to estimate the plastic strain ratio (r-value) by DIC technique. In addition, the preparing of sheet specimens has three difference directions that were parallel, transverse, and $45^{\circ}$ to the rolling direction. After the tests, the results determined the Young's modulus $(E), 0.2 \%$ offset yield strength $(Y)$, ultimate tensile strength $\left(\sigma_{u}\right)$, total elongation $(\varepsilon)$, and plastic strain ratio. Moreover, it has been able to determine the work-hardening exponent $(n)$ and the strength coefficients $(K)$ of parallel to the rolling direction, all parameters that shown in Table 3.

Table 3. Mechanical properties of NSC980D steel from tensile testing

\begin{tabular}{|c|c|c|c|c|c|c|c|}
\hline $\begin{array}{c}\text { Dir } \\
\text { ect } \\
\text { ion }\end{array}$ & $\begin{array}{c}\boldsymbol{E} \\
{[\mathbf{G P a}} \\
]\end{array}$ & $\begin{array}{c}\boldsymbol{Y} \\
{[\mathbf{M P}} \\
\mathbf{a}]\end{array}$ & $\begin{array}{c}\boldsymbol{\sigma}_{\boldsymbol{u}} \\
{[\mathbf{M P a}]}\end{array}$ & $\begin{array}{c}\boldsymbol{\varepsilon} \\
{[\%]}\end{array}$ & $\boldsymbol{n}$ & $\begin{array}{c}\boldsymbol{K} \\
{[\mathbf{M}} \\
\mathbf{P a} \\
{[}\end{array}$ & $\mathbf{r}$ \\
\hline $0^{\circ}$ & $\begin{array}{c}189.7 \\
6\end{array}$ & $\begin{array}{c}670.5 \\
7\end{array}$ & 946.84 & 10.05 & $\begin{array}{c}0.10 \\
24\end{array}$ & $\begin{array}{c}1324 \\
.47\end{array}$ & 0.82 \\
\hline $45^{\circ}$ & $\begin{array}{c}188.9 \\
9\end{array}$ & $\begin{array}{c}761.0 \\
3\end{array}$ & 1079.85 & 10.68 & $\mathrm{~N} / \mathrm{A}$ & $\begin{array}{c}\mathrm{N} / \\
\mathrm{A}\end{array}$ & 0.83 \\
\hline $90^{\circ}$ & $\begin{array}{c}190.9 \\
8\end{array}$ & $\begin{array}{c}770.1 \\
8\end{array}$ & 1032.29 & 10.04 & $\mathrm{~N} / \mathrm{A}$ & $\begin{array}{c}\mathrm{N} / \\
\mathrm{A}\end{array}$ & 0.92 \\
\hline $\begin{array}{c}\mathrm{Av} \\
\mathrm{g} .\end{array}$ & $\begin{array}{c}189.9 \\
1\end{array}$ & $\begin{array}{c}733.9 \\
2\end{array}$ & 1019.66 & 10.26 & $\mathrm{~N} / \mathrm{A}$ & $\begin{array}{c}\mathrm{N} / \\
\mathrm{A}\end{array}$ & 0.86 \\
\hline
\end{tabular}

\subsection{FE element}

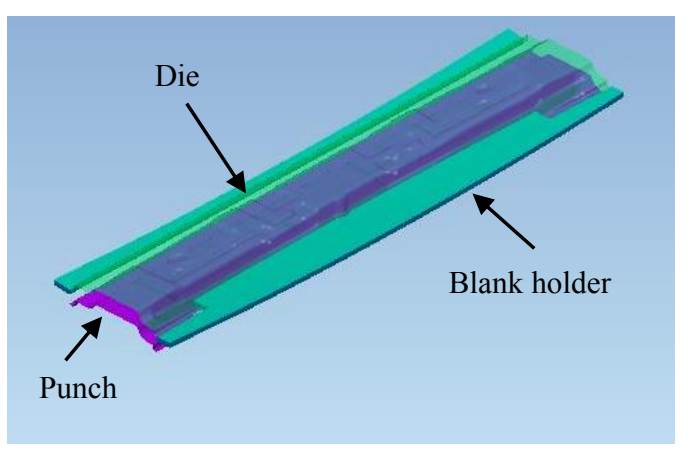

Figure 2. The FE model design by PAM-STAMP 
In this work, study on Panel-RF FRT HRD component, it was automotive roof frame, and used the commercial program was PAM-STAMP to design 3D FE model, predicting and improving the die compensation for solve the spring-back effect. The position of tools shown as Figure 2. The thickness of blank was $1.0 \mathrm{~mm}$ by definite the blank size was $225 \mathrm{~mm}$ in width and $1000 \mathrm{~mm}$ in length. To create the finite element of the initial blank material with parameters of material model from mechanical testing, the mesh quality has been ensured to reliability for FE simulation. The initial mesh size was 14 $\mathrm{mm}$ and final mesh size was $0.875 \mathrm{~mm}$. The refinement mesh size has maximum level was 5 . The setting of drawing condition for FE simulation, has been set up with the stamping velocity was $5 \mathrm{~m} / \mathrm{s}$ and the holding velocity was $2 \mathrm{~m} / \mathrm{s}$. The friction coefficient of die/punch and blank holder was definite to 0.1 . The cushion stroke which the initial rise of the blank holder was set to $40 \mathrm{~mm}$ and while FE simulation forming that use blank holding force at 9 tons. The overall of drawing process is single action. And Figure 3 showed the FE simulation model step [5]. In Step one was the gravity step. The blank was placed on the blank holder by only gravity force. Next, the holding step was the upper die hold on the blank and contact the blank holder. Third, stamping step, the blank was deformed into final product of forming process. After the forming step, the spring-back simulation was proceeded. FE simulation in this research, has been used with material models for compare the spring-back prediction such as Y-U model, Hill'48 and 980_GEN3_GPa which was the materials parameters in PAM-STAMP

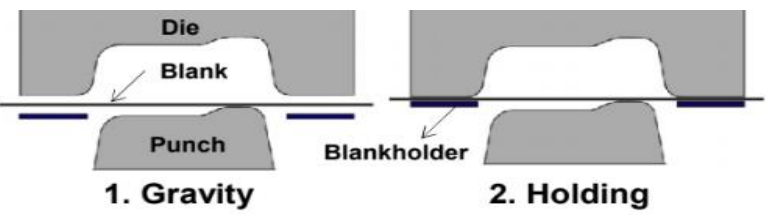

3. Stamping

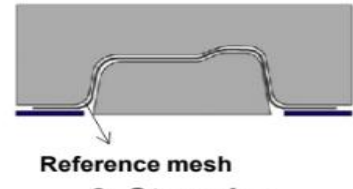

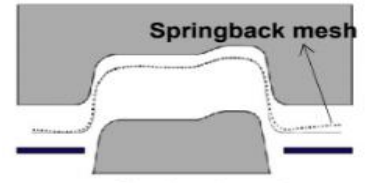

4. Springback
Figure 3. The diagram of forming state

\subsection{Drawing process}

To prove the material parameters from testing, Y-U model was predicted the spring-back effect. Automotive component was better than other model and close to the actual forming test with the same condition and die design as the forming simulation. The actual automotive component, Panel-RF FRT HRD is shown as Figure 4.

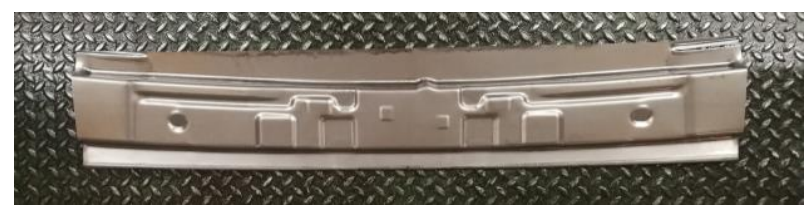

Figure 4. The actual product of Panel-RF FRT HRD

\subsection{Spring-back comparison}

In FE simulation and forming test of automotive component. The researcher used $3 \mathrm{D}$ file, which the actual product had been converted with 3D scanning, for compare the spring-back effect by cross-section of actual and simulation products. Considering with 3 sections, section A was $150 \mathrm{~mm}$ from the left, and section B was the center of product and section $\mathrm{C}$ was $300 \mathrm{~mm}$ from the right. Figure 5 showed each section that considered. The next step, the researcher used the sections to evaluation of angle variable to predict and compare the spring-back effect as shown in Figure 6.

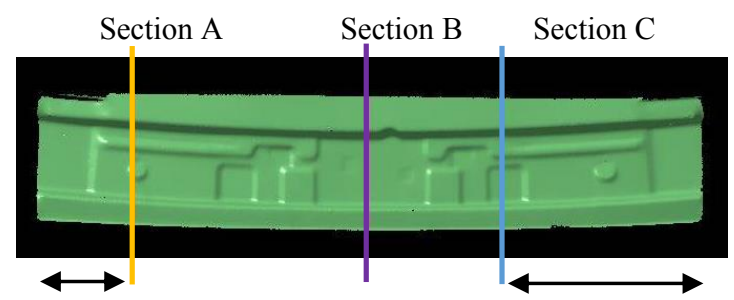

$150 \mathrm{~mm}$

$300 \mathrm{~mm}$

Figure 5. The section for spring-back comparison

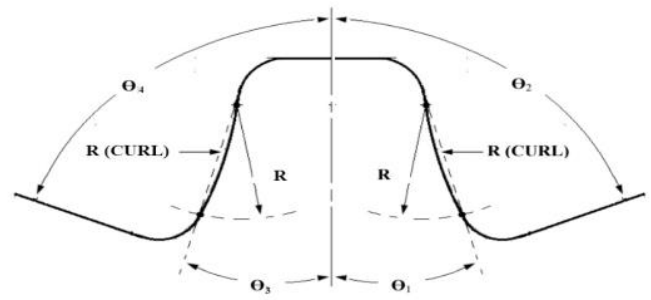

Figure 6. The variables for spring-back evaluating

\section{Result and discussion}

The research product performed by FE simulation with different material model such as Y-U model, Hill's 48 and 980_GEN3_GPa focused on spring-back effect considering with displacement along direction contour. A result of $\mathrm{Y}-\mathrm{U}$ model simulation was observed that the local maximum and minimum deviation due to the spring-back were $6.844 \mathrm{~mm}$ and $-5.239 \mathrm{~mm}$ by respectively at the end of product as shown in Figure 7.

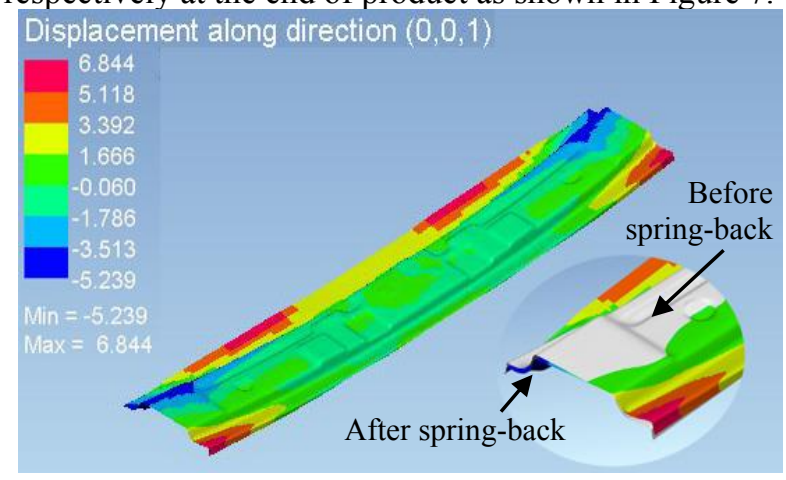

Figure 7. The comparison of before and after spring-back effect of Y-U simulation 
Then, Figure 8 showed the local maximum deviation of spring-back was $6.368 \mathrm{~mm}$ at the end of product and the minimum spring-back was $-2.567 \mathrm{~mm}$ was more at the center of product that was the results of Hill's 48 model simulation.

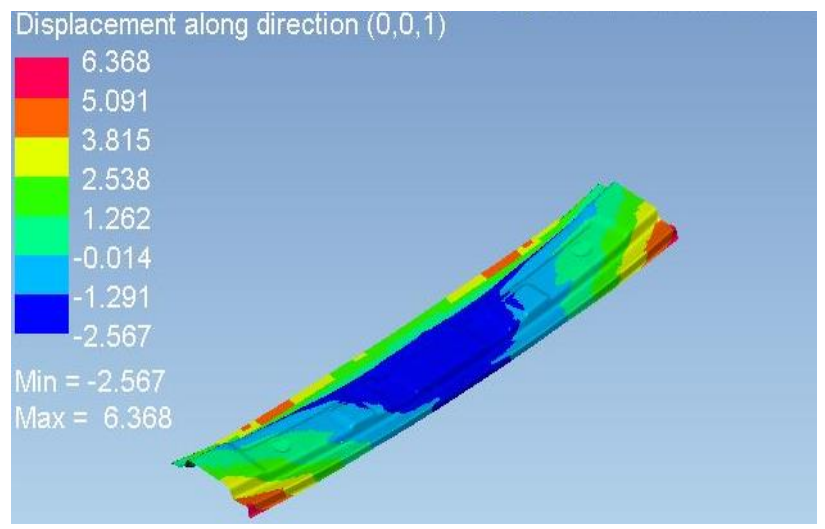

Figure 8. The displacement along direction of the Hill's 48 model simulation

For the 980_GEN3_GPa material parameters was detected that the local maximum and minimum of springback ordered was $5.368 \mathrm{~mm}$ and $-1.784 \mathrm{~mm}$, the area where has spring-back been similar with a result of Hill's 48 model. The displacement along direction of 980_GEN3_GPa simulation is shown as Figure 9.

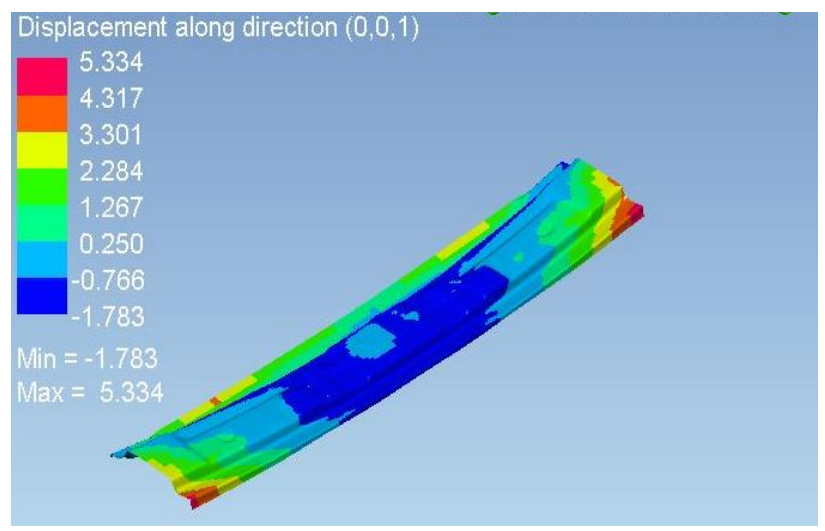

Figure 9. The displacement along direction of the 980 GEN GPa simulation

In case of cross section profile for comparing the angle of spring-back from the experiment and simulation with each material model parameters showed that the result of Y-U material model simulation has been closely with actual experiment more than another, the Figure 1012 shown as a comparison of experiment and each material model parameters cross section, in section A, B and $\mathrm{C}$.

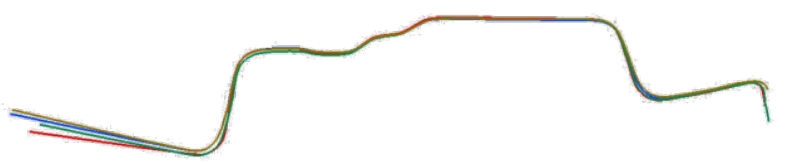

Figure 10. The comparison of cross section profile in section A

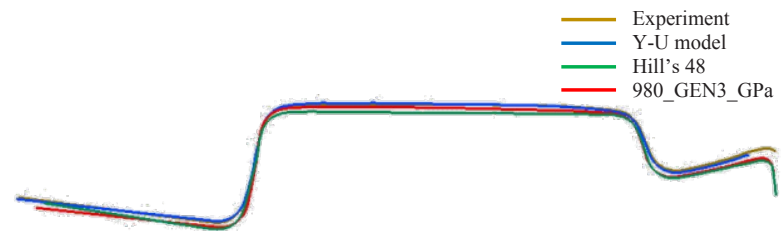

Figure 11. The comparison of cross section profile in section B

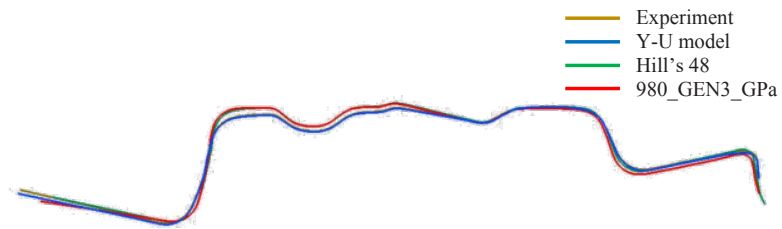

Figure 12. The comparison of cross section profile in section $\mathrm{C}$

In Figure 13, it was clearly shown the difference in predictor of spring-back effect, when prepares with the actual experiment forming.
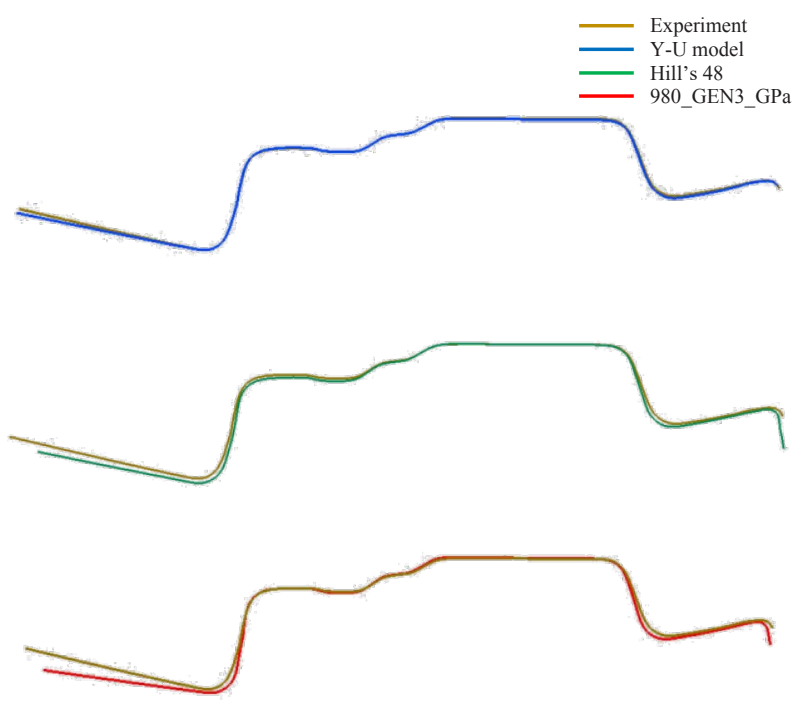

Figure 13. The comparison of each model section prepares with experiment in section $\mathrm{C}$

And from the angle comparing, as shown in Figure 6, it is found Y-U model simulation has the effect of deviating from the actual part was less than another model; the maximum deviation was 4.84 degrees, the minimum deviation was 0.16 degrees and the average deviation was 1.26 degrees. While the Hill's 48 model has the maximum deviation was 5.56 degrees, the minimum deviation was 0.83 and the average deviation was 2.93 degrees. As same as the 980_GEN3_GPA has the maximum deviation was 5.35 degrees, the minimum deviation was 0.83 and the average deviation was 2.54 degrees.

\section{Conclusion}

From materials tested by static tensile and tensioncompression made many materials parameters to use in materials model such as Y-U model and Hill's 48. Exceptionally, 980_GEN3_GPa was a material parameter from PAM-STAMP program. This research could apply to study on NSC980D steel for automotive component 
forming, which is Panel-RF FRT HRD. The investigation was found that Y-U model was appropriated to use finite element simulation for prediction the spring-back of AHS steel which was better than another materials model because research study was shown the result of Y-U simulation closely with actual experiment. This kinematic hardening materials model was consisted of seven plasticity material parameters and three parameters of Young's modulus parameters, which could be described the behavior of AHS steel.

\section{Acknowledgment}

This research has been funded by the Thailand Research Fund (TRF) and Research and Researcher for Industries (RRi). Moreover, the author was supported material from Thai Summit Automotive Co., Ltd.

\section{References}

1. W. Gan, S. S. Babu, N. Kapustka and H. Robert: Microstructural effects on the spring-back of advanced high-strength steel, Metallurgy and
Materials Transations A. Vol. 37 (2006), p. 32213231 .

2. P. Chen and M. Koç: Simulation of springback variation in forming of advanced high strength steels, J. Mater. Pro. Tech. Vol. 190 (2007), p. 189-198.

3. F. Pourboghrat and E. Chu: Prediction of spring-back and side wall curl in 2-D draw bending, J. Mater. Pro. Tech. Vol. 50 (1995), p.361-374.

4. F. Yoshida and T. Uemori, in:Cyclic plasticity model for accurate simulation of spring-back of sheet metal, 60 Excellent Inventions in metal Forming, edited by A. E. Tekkaya, W Homberg and A. Brosius Publising. Berlin, Heidlberg (2015). P. 61-66.

5. PAM-STAMP 2G Profession 64-Bit Program.

6. E. M. Lee, D. S. Shim and et al: Study on design of progressive dies for manufacture of aotomoblie strctural member using DP980 advancd high strengtg steel, J. Mech. Sci. Tech. Vol. 30 (2016), p. 853-864.

7. W. Julsri, S. Suranuntchai and V. Uthaisangsuk: Study of spring-back effect of AHS steel using a microstucture based modelling, Int. J. Mech. Sci. Vol. 135 (2017), p. 499-516. 